\title{
Are Soil Pollution Risks Established by Governments the Same as Actual Risks?
}

\author{
L. Reijnders \\ IBED, University of Amsterdam, Nieuwe Achtergracht 166, 1018 WV Amsterdam, The Netherlands \\ Correspondence should be addressed to L. Reijnders, 1.reijnders@uva.nl
}

Received 26 February 2009; Accepted 20 July 2009

Recommended by Amarilis de Varennes

\begin{abstract}
Though soil pollution policies in North America and the European Union increasingly use risk-based standards, the construction and application of such standards are often deficient in taking account of actual risks. Standards refer to total concentrations of substances and not to the biologically available amount. A number of countries neglect "background" exposure, and assumptions regarding routes of exposure to soil pollution can be very different and at variance with empirical data. Recent dose-effect studies are neglected in a number of cases. The application of standards does not take account of the overall risk of soil pollution but rather leads to the decision whether or not there is violation of at least one standard for a specified (group of) substance(s). Standards for soil pollutants are often based on the assumption that only effect addition can occur, whereas dose addition, antagonism and synergism, and indirect effects may in fact apply. Several remedies for current shortcomings are proposed.
\end{abstract}

Copyright $\odot 2009$ L. Reijnders. This is an open access article distributed under the Creative Commons Attribution License, which permits unrestricted use, distribution, and reproduction in any medium, provided the original work is properly cited.

\section{Introduction}

There is an increasing use of risk-oriented policies to deal with the local effects of soil pollution. The risks that such policies deal with are human health risks and can also include ecotoxicological risks. These risks are expressed in terms of negative effects and chances between 0 and 1 that such negative effects will occur. Examples of areas where riskoriented policies are applied to soil pollution include the United States of America [1, 2], Canada [3], and countries in the European Union [4-10]. Historically, these riskoriented policies have followed the abandonment of policies aimed at restoring soils to their original "clean" state (e.g., [5]).

Risk-based criteria or standards, developed in the framework of risk-oriented policies, are applied to risks estimated with deterministic methodologies, following the steps of hazard characterization, appraisal of exposure, and risk characterization, while using exposure-risk relations established beforehand. Risk-based criteria have been applied to decisions about soil remediation in the form of soil cleanup standards $[2,9,10]$, to the use of soils for specific purposes $[11,12]$, and in the United States also to sediment management [13]. The risk-oriented policies considered here [1-13], assume that background exposure to pollutants carries no risk and that a specified level of soil pollution carries a maximum tolerable or maximum acceptable risk for organisms living locally. The latter is the main basis for standard setting.

In part, risk-oriented soil pollution legislation includes policy goals that are qualitative [10]. For instance, the primary UK legislation on contaminated soil defines land as contaminated in need of risk management "if significant harm is being caused or there is a significant possibility of such harm being caused" [10]. Mostly, however policies have resulted in specific quantitative values for maximum tolerable or acceptable soil pollution. The analysis of such values used in different industrialized countries has shown that there are very large differences, roughly up to a factor $10^{4}[14,15]$. According to Provoost et al. [14, 15], these differences to a large extent originate in different political choices (e.g., including or excluding ecotoxicity) and in different assumptions as to the modeling of exposure to soil pollutants, including site related factors, such as soil type and building constructions $[14,15]$.

This paper deals with the way in which governments establish risk and with the question whether what governments establish reflects actual risk. 
A part of the large divergence in standards for maximum tolerable or acceptable risk originates in between-country differences in political choices (about what is tolerable or acceptable), soil types and building constructions. In principle, these differences do not lead to divergence between risk as established by governments and actual risk.

However other factors may lead to such divergence. An example thereof is the parameters used for modeling exposure to soil pollutants given specific exposure routes. The differences in these parameters will not be considered here, as this subject has been extensively dealt with by Provoost et al. $[14,15]$. Here the focus will be on another source for the divergence between risks as established by governments and actual risks.

In dealing with the risks of soil pollution, it would seem obvious to address the overall risk of the soil pollutants present to the extent that they are biologically available for specific organisms, against the background of exposure from other sources. However actual practice is often different.

Firstly, in Section 2 shortcomings in current governmental risk estimates will be discussed regarding exposure to a single pollutant focusing on the presence of soil quality standards, exposures to all sources of the pollutant at hand, the account taken of recent dose-effect studies, and biological availability.

Secondly, in Section 3 the matter of combination effects of soil pollutants will be considered. In Section 4, several remedies for current shortcomings will be proposed. Section 5 summarizes the conclusions of this paper.

\section{Risks Related to One Soil Pollutant}

In practice, there are several matters which are at variance with the proper establishment of actual risk related to one soil pollutant. These are the absence of standards for pollutants, neglect of background exposure, neglect of routes of exposure to soil pollution, neglect of available dose-effect studies and neglect of biological availability. These will now be discussed in more detail.

2.1. Absence of Quality Standards. When data regarding soil pollutants are available, they should be compared with quality standards reflecting maximum tolerable risk of exposure. However, such standards are not always in place. For instance, of the volatile organic carbon compounds detected in groundwater samples by the US Geological Service, 21 were unregulated-with no standards in place [16]. Similarly Patterson et al. [17] found a variety of brominated ethenes in Australian groundwater, all lacking standards. In the Netherlands there are no standards for heterocyclic polycyclic aromatics, though these can be a substantial contributor to soil and sediment pollution risk [18].

When there is no standard, the government policies considered here [1-13] tend to neglect the soil pollutant involved. This may lead to a divergence between risk as established by governments and actual risks.
2.2. Neglect of Background Exposure. For a proper estimate of soil pollution related risks, exposure to specific soil pollutants should be evaluated in combination with exposure to the same substance that is not related to local soil contamination. Several countries, such as Canada, Germany, Spain, and Belgium, do indeed establish soil clean-up standards while considering background dietary and inhalatory exposure but others, for example, Sweden, Norway, and the Netherlands, do not $[9,14]$. Neglecting background exposure or specific types of background exposure may have implications for risk estimates, as will be elaborated in Section 2.4.

2.3. Neglect of Routes of Exposure to Soil Pollution. In evaluating exposure to soil pollutants, assumptions regarding exposure routes are important. In this respect difference between countries may be noted. Soil clean-up standards for lead of Norway and Sweden differ in part because in Sweden the dominant exposure route is assumed to be by drinking water, and in Norway it is thought to be by drinking water, and ingestion of soil [14]. These differences cannot be explained by differences in habits between Swedes and Norwegians and at least one of these assumptions must be at variance with actual exposure patterns.

Inhalation of household dust and soil particles is not always taken into account in governmental decision making about risks of soil pollution. For instance, in the Netherlands inhalation of soil particles has been neglected as an exposure route, but in for example, Spain it is not [9]. Neglect of inhalation would seem at variance with existing studies. Nawrot et al. [19] have studied the effects of cadmium pollution in soil (around former thermal zinc plants) and found a significant increase in lung cancer risk correlated with cadmium exposure. They plausibly explain this in terms of exposure of lung tissue to cadmium present in inhaled soil and household dust particles. Household dust particles have also been found to be important in the exposure of children to pesticides in agricultural settings [20]. Studies of Laidlaw et al. [21, 22] suggest that inhalation of soil particles containing lead may be important in determining the body burden of lead in American cities. Increasing urban body burdens of lead have been shown to be correlated with neurodevelopmental toxicity [23].

\subsection{Neglect of Available Dose-Effect Studies}

2.4.1. Dose-Effect Studies Relevant to Humans. As pointed out in the Introduction, it is assumed in soil pollution policy that background exposure represents no risk. This neglects a number of epidemiological studies that have been done regarding background exposure, and more generally reflects deficiencies in the use of available dose-effect studies in determining actual risk.

Akesson et al. [24] have analyzed the effects of low environmental cadmium exposure in an epidemiological study of Swedish women in the Lund area, being 53-64 years of age, excluding women from areas with soils heavily polluted by cadmium. Akesson et al. [24] found associations between 
the internal dose of cadmium and tubular and glomerular kidney effects, which may represent early signs of adverse effects. Women with diabetes seemed to be at increased risk of experiencing such early signs. In view of these data it seems plausible that at a background exposure that is common in Sweden, old women in the general population may be at risk for adverse cadmium effects [25] and that even a modest increase in cadmium exposure due to polluted soil may lead to added risk. However, when establishing soil clean-up standards in Sweden this background exposure has been neglected [14]. Nawrot et al. [26] have studied the relation between mortality and cadmium body burden in Belgium. They obtained evidence that total mortality and noncardiovascular mortality may be elevated at cadmium body burdens which can be found among the population not living on soils that are currently considered to be a health risk.

Similarly there are now strong indications that the negative effects of lead on the neurophysiological and sexual development may well be found at the level of background exposure common in Western European and US cities [2732], though soil pollution policy, at least in European counties, assumes that such background exposure is safe [14].

A study of women from the general population in France found that calcium pump activity in their newborns negatively correlated with hair mercury levels, and this may well be responsible for subtle neurobehavioral deficits of children in the general population that also correlate with mercury levels $[33,34]$. There is also evidence for negative cardiovascular effects of methylmercury in the adult general population of industrial countries [34]. Again this is not reflected in risk estimates within the framework of soil pollution policies in European countries [14]. A study regarding exposure of the general population in the Netherlands to PCBs and halogenated dioxins and benzofurans suggests reduced lung function, retarded brain development, and a negative haematological impact [25].

2.4.2. Ecotoxicological Risks. Maximum acceptable or maximum tolerable ecotoxicological risks are usually derived from a limited number of studies concerning single species under laboratory conditions. Laboratory conditions may be very different from actual conditions in the field, and thus findings in the field are often at variance with laboratory studies $[18,35]$. In field studies it has been found that several factors which tend to be neglected in laboratory studies may strongly impact toxic effects of soil pollutants. These include among others: density and adaptability of populations of affected organisms, the presence of other environmental stress factors, and the presence or absence of specific landscape elements such as buffer strips $[18,35]$.

2.5. Biological Availability. Biologically available pollutants determine risk [3]. Biological availability may vary strongly for different types of organisms [36]. Biological availability of a compound in a specific soil is also dependent on physical, chemical, and biological and spatial factors $[3,35]$. Examples of such factors are $\mathrm{pH}$, the amount and nature of organic and mineral compounds also present and the presence of organisms which can mobilize soil pollutants [35, 37-39]. In practice, biological availability may be much at variance with total concentrations [40].

However standards reflecting potentially unacceptable risk tend to refer to total concentrations. In the case of elements (such as heavy metals), moreover standards often do not refer to specific compounds though it may well be that the nature of the compound is a determinant of biological availability. To the limited extent that biological availability is considered in site specific follow up studies, in vitro tests are used that may give rise to estimates that are at variance with in vivo biological availability [3].

\section{Combination Effects}

3.1. Limited Accounting of Combination Effects. As to the overall risk of soil pollutants, the US Comprehensive Environmental Response, Compensation and Liability Act (1990) stipulates that cumulative effects of the combination of substances present in soils should be considered. However actual standard setting practice has largely focused on criteria relating to one element or compound. In some cases there are criteria for groups of compounds [4]. Such criteria limit the amount (in $\mathrm{g} / \mathrm{kg}$ soil) of groups of compounds but often do not address the possibility that the risk per unit of weight may be different for different compounds. An exception to this is criteria for the presence of halogenated dioxins and benzofurans and planar biphenyls. The establishment of risk in case of exposure to these compounds uses addition on the basis of equivalent toxicity [4]. This is a major improvement, though it has been pointed out that this approach may still underestimate the risk of neurodevelopmental effects [41].

In the Netherlands, according to Van Zorge [4], the consideration of combination effects has led to introducing an additional safety factor. Indeed, apart from a level of maximum tolerable or acceptable risk, a level of negligible risk has been defined which reflects the use of a safety factor for combination effects. However in actual Dutch policy decisions, such as the decision to clean up soils, the legal basis usually necessitates a focus on exceeding maximum tolerable risk levels for individual substances, when deciding whether soil pollution should be considered for remediation [4]. Exceeding negligible risk standards is in The Netherlands not a basis for government intervention [42].

3.2. Importance of Combination Effects. Combination effects may be important in two respects. Firstly, coexisting soil contaminants may impact each others' biological availability [43]. Secondly, exposure to a combination of pollutants may be associated with antagonistic, synergistic and additive interactions of these pollutants, impacting their effect on organisms [44-47]. Some risks of pollutant mixtures can be predicted on the basis of existing knowledge. For instance there is a fair chance that there will be dose additivity when effects are receptor mediated [48]. Also in case of 
narcotic effects, joint-mixture ecotoxicological effects may be predicted [48]. If responses are dissimilar, response addition may be used [49]. A methodology to deal with the ecotoxicity of mixtures giving rise to both dose-additive and responseadditive effects has been proposed [48]. This two-step model evaluates mixture toxicity for the same mode of action with concentration additivity and the toxicity for different modes of action with response additivity. For determining the severity of ecotoxicological effects in case of heavily polluted soils (in which legal maximum tolerable levels for one or more substances are exceeded), a systematic approach to combination effects based on a mixture of concentration addition and response addition has been proposed [41].

However, it should be noted that responses of ecosystems in the field may well diverge from estimates made on the basis of additivity, for example, due to mobility of organisms, density dependent effects or indirect effects such as secondary poisoning and trophic effects following from lowered abundance of food sources $[35,50]$. Also synergism may occur $[45,47]$. Including such factors is not easy. More sophisticated modeling may still lead to results that are widely of the mark in the real world [36].

\section{Remedies for Shortcomings}

From Sections 2 and 3 one may conclude that risks established within the framework of current risk-oriented soil pollution policies tend to be at variance with actual risks. This undermines the credibility of such policies and may be argued to be a good reason for abandoning riskoriented policies or for correcting the shortcomings outlined in Sections 2 and 3. Possible remedies for these shortcomings will be outlined here. It should be realized that much scientific work will be required in order to make these remedies operational.

Remedies would seem possible which would allow for a significant improvement in risk estimates. Unregulated substances can get standards. Standards may be regularly updated on the basis of new dose-effect studies. Risk estimates can include both background exposure and all exposure routes for local soil pollution. Estimates of biological availability can be integrated in risk assessments and improved by better testing of bioavailability or by in vivo monitoring $[3,51]$.

The deficiencies in taking account of combination effects in ecotoxicity, discussed in Section 3, may be addressed by direct testing of ecotoxicity, when the focus is on ecosystem functioning $[52,53]$. However it should be noted that small effects on the functioning of ecosystems may have large effects over time [35]. This necessitates large numbers of replicate tests that may well be beyond routine practice [35].

In determining combination effects on human health, direct testing on humans is an "unethical option". However biomarker-based monitoring of some aspects of soil pollution relevant to humans may be an option. For instance Roos et al. [54] have applied a biomarker based test to original and remediated soils that were contaminated by a variety of polycyclic aromatic hydrocarbons (PAH). They tested the expression profile of cytochrome P 450 [54]. Xiao et al. [55] have measured genotoxic risk of soil contamination using an in vitro assay with Salmonella. Though the relation between such biomarker-based data gathered and the in vivo risks awaits further elucidation, the application of tests based on biomarkers for soil pollution is an interesting option in dealing with combination effects on humans.

Also, estimates of risk may be derived from biomarkers which may be monitored in people exposed to soil pollution. Such biomarkers have emerged from epidemiological studies considering the combined effect of substances. An illustration thereof is the study by Lee et al. [56] which found a graded association of the concentration of blood lead and urinary cadmium concentrations with oxidative stress related markers in the US population. This suggests that oxidative stress may be useful as a biomarker for combination effects. It has furthermore been proposed to evaluate effects of exposure to nitroarenes by measuring haemoglobin adducts [57], and of mixtures of volatile organochlorines by measuring glutathione conjugative metabolites [58]. Bioassays based on aryl hydrocarbon (Ah) receptor mediated mechanisms have been proposed which will allow a better alternative to the measurement of polyhalogenated aromatic hydrocarbons [41].

Another option is to estimate risks to human health by taking into account cumulative combination effects in line with established cause-effect relations and research into the effects of actual combinations. It has been shown that risks of compounds with the same targets and the same modes of action may be estimated on the basis of concentration addition, while including toxicity equivalence factors for the compounds involved [59]. This has been shown to apply to receptor-mediated-and reactive mechanisms of toxicity, provided that no chemical reactions occur between the components of the mixture considered [5, 60]. Currently this approach is applied to halogenated dioxins, benzofurans, and planar polybiphenyls, though nonlinear interactions are not completely absent in this category of compounds [61], and neurodevelopmental effects may be underestimated, as pointed out before [41]. Extension of this approach is possible to for example, polycyclic aromatics, including heterocyclic polycyclic aromatics $[18,62]$ organophosphates that inhibit the enzyme cholinesterase [44, 63], compounds that bind to estrogen receptors [64-66], carcinogens [67], a variety of petroleum products [68], and compounds that inhibit the MXR efflux pump [69].

\section{Conclusion}

The construction and application of risk-based standards for soil pollution are often deficient in taking account of actual risks. Standards refer to total concentrations of substances and not to the biologically available amount. A number of countries neglect "background" exposure, and assumptions regarding routes of exposure to soil pollution can be very different. Recent dose-effect studies are neglected in a number of cases. The application of standards does not take 
account of the overall risk of soil pollution, but rather leads to the decision whether or not there is violation of at least one standard for a specified (group of) substance(s). Excepting halogenated dioxins, benzofurans and planar biphenyls, criteria for soil pollutants are based on the assumption that only effect addition can occur, whereas dose addition, antagonism, and synergism and indirect effects may in fact apply.

Several remedies to these shortcomings have been proposed. Regarding ecotoxicity direct testing would allow for a major improvement in risk estimates. As to human health risks, including biological availability in risk estimates, more use of up to date knowledge about exposure routes, doseeffect relations and combination effects, and biomonitoring of effects are options for improvement.

\section{Acknowledgment}

The comments of two anonymous reviewers are gratefully acknowledged.

\section{References}

[1] D. Okrent, "On intergenerational equity and its clash with intragenerational equity and on the need for policies to guide the regulation of disposal of wastes and other activities posing very long-term risks," Risk Analysis, vol. 19, no. 5, pp. 877-901, 1999.

[2] D. A. Belluck, S. L. Benjamin, P. Baveye, J. Sampson, and B. Johnson, "Widespread arsenic contamination of soils in residential areas and public spaces: an emerging regulatory or medical crisis?" International Journal of Toxicology, vol. 22, no. 2, pp. 109-128, 2003.

[3] G. M. Richardson, D. A. Bright, and M. Dodd, "Do current standards of practice in Canada measure what is relevant to human exposure at contaminated sites? II: oral bioaccessibility of contaminants in soil," Human and Ecological Risk Assessment, vol. 12, no. 3, pp. 606-616, 2006.

[4] J. A. Van Zorge, "Exposure to mixtures of chemical substances: is there a need for regulations?" Food and Chemical Toxicology, vol. 34, no. 11-12, pp. 1033-1036, 1996.

[5] F. A. Swartjes, "Risk-based assessment of soil and groundwater quality in the Netherlands: standards and remediation urgency," Risk Analysis, vol. 19, no. 6, pp. 1235-1249, 1999.

[6] R. T. Eikelboom, E. Ruwiel, and J. J. J. M. Goumans, "The building materials decree: an example of a Dutch regulation based on the potential impact of materials on the environment," Waste Management, vol. 21, no. 3, pp. 295-302, 2001.

[7] M. Crane and J. M. Giddings, "“"Ecologically acceptable concentrations" when assessing the environmental risks of pesticides under European directive 91/414/EEC," Human and Ecological Risk Assessment, vol. 10, no. 4, pp. 733-747, 2004.

[8] P. Nathanail, C. McCaffrey, N. Earl, N. D. Foster, A. G. Gillett, and R. Ogden, "A deterministic method for deriving sitespecific human health assessment criteria for contaminants in soil," Human and Ecological Risk Assessment, vol. 11, no. 2, pp. 389-410, 2005.

[9] J. V. Tarazona, M. D. Fernandez, and M. M. Vega, "Regulation of contaminated soils in Spain. A new legal instrument," Journal of Soils and Sediments, vol. 5, no. 2, pp. 121-124, 2005.
[10] J. Evans, G. Wood, and A. Miller, "The risk assessment-policy gap: an example from the UK contaminated land regime," Environment International, vol. 32, no. 8, pp. 1066-1071, 2006.

[11] J. T. M. Huinink, "Soil quality requirements for use in urban environments," Soil and Tillage Research, vol. 47, no. 1-2, pp. 157-162, 1998.

[12] A. Urzelai, M. Vega, and E. Angulo, "Deriving ecological riskbased soil quality values in the Basque Country," Science of the Total Environment, vol. 247, no. 2-3, pp. 279-284, 2000.

[13] S. E. Apitz, "Is risk-based, sustainable sediment management consistent with European policy?" Journal of Soils and Sediments, vol. 8, no. 6, pp. 461-466, 2008.

[14] J. Provoost, C. Cornelis, and F. Swartjes, "Comparison of soil clean-up standards for trace elements between countries: why do they differ?" Journal of Soils and Sediments, vol. 6, no. 3, pp. 173-181, 2006.

[15] J. Provoost, L. Reijnders, F. Swartjes, et al., "Parameters causing variation between soil screening values and the effect of harmonization," Journal of Soils and Sediments, vol. 8, no. 5, pp. 298-311, 2008.

[16] P. L. Toccalino and J. E. Norman, "Health-based screening levels to evaluate U.S. Geological Survey ground water quality data," Risk Analysis, vol. 26, no. 5, pp. 1339-1348, 2006.

[17] B. M. Patterson, E. Cohen, H. Prommer, D. G. Thomas, S. Rhodes, and A. J. McKinley, "Origin of a mixed brominated ethene groundwater plume: contaminant degradation pathways and reactions," Environmental Science \& Technology, vol. 41, no. 4, pp. 1352-1358, 2007.

[18] M. Leon Paumen, Invertebrate life cycle responses to PAC exposure, Ph.D. thesis, University of Amsterdam, Amsterdam, The Netherlands, 2008.

[19] T. Nawrot, M. Plusquin, J. Hogervorst, et al., "Environmental exposure to cadmium and risk of cancer: a prospective population-based study," The Lancet Oncology, vol. 7, no. 2, pp. 119-126, 2006.

[20] N. J. Simcox, R. A. Fenske, S. A. Wolz, I.-C. Lee, and D. A. Kalman, "Pesticides in household dust and soil: exposure pathways for children of agricultural families," Environmental Health Perspectives, vol. 103, no. 12, pp. 1126-1134, 1995.

[21] M. A. S. Laidlaw, H. W. Mielke, G. M. Filippelli, D. L. Johnson, and C. R. Gonzales, "Seasonality and children's blood lead levels: developing a predictive model using climatic variables and blood lead data from Indianapolis, Indiana, Syracuse, New York, and New Orleans, Louisiana (USA)," Environmental Health Perspectives, vol. 113, no. 6, pp. 793-800, 2005.

[22] M. A. S. Laidlaw, H. W. Mielke, G. M. Filippelli, and D. L. Johnson, "Blood lead in children: Laidlaw et al. respond," Environmental Health Perspectives, vol. 114, no. 1, p. A19, 2006.

[23] S. J. Rothenberg and J. C. Rothenberg, "Testing the doseresponse specification in epidemiology: public health and policy consequences for lead," Environmental Health Perspectives, vol. 113, no. 9, pp. 1190-1195, 2005.

[24] A. Akesson, T. Lundh, M. Vahter, et al., "Tubular and glomerular kidney effects in Swedish women with low environmental cadmium exposure," Environmental Health Perspectives, vol. 113, no. 11, pp. 1627-1631, 2005.

[25] G. W. ten Tusscher, Later childhood effects of perinatal exposure to background levels of dioxins in the Netherlands, Ph.D. thesis, University of Amsterdam, Amsterdam, The Netherlands, 2002.

[26] T. S. Nawrot, E. van Hecke, L. Thijs, et al., "Cadmiumrelated mortality and long-term secular trends in the cadmium 
body burden of an environmentally exposed population," Environmental Health Perspectives, vol. 116, no. 12, pp. 16201628, 2008.

[27] B. P. Lanphear, K. Dietrich, P. Auinger, and C. Cox, "Cognitive deficits associated with blood lead concentrations $<10$ microg/dL in US children and adolescents," Public Health Reports, vol. 115, no. 6, pp. 521-529, 2000.

[28] C.-L. Wang, H.-Y. Chuang, C.-K. Ho, et al., "Relationship between blood lead concentrations and learning achievement among primary school children in Taiwan," Environmental Research A, vol. 89, no. 1, pp. 12-18, 2002.

[29] T. Wu, G. M. Buck, and P. Mendola, "Blood lead and sexual maturation in U.S. girls: the third national health and nutrition examination survey, 1988-1994," Environmental Health Perspectives, vol. 111, no. 5, pp. 737-741, 2003.

[30] H. Von Storch, M. Costa-Cabral, C. Hagner, et al., "Four decades of gasoline lead emissions and control policies in Europe: a retrospective assessment," Science of the Total Environment, vol. 311, no. 1-3, pp. 151-176, 2003.

[31] H. W. Mielke, C. R. Gonzales, E. Powell, M. Jartun, and P. W. Mielke Jr., "Nonlinear association between soil lead and blood lead of children in metropolitan New Orleans, Louisiana: 2000-2005," Science of the Total Environment, vol. 388, no. 1-3, pp. 43-53, 2007.

[32] M. L. Miranda, D. Kim, M. A. Overstreet Galeano, C. J. Paul, A. P. Hull, and S. P. Morgan, "The relationship between early childhood blood lead levels and performance on end-of-grade tests," Environmental Health Perspectives, vol. 115, no. 8, pp. 1242-1247, 2007.

[33] G. Huel, J. Sahuquillo, G. Debotte, J.-F. Oury, and L. Takser, "Hair mercury negatively correlates with calcium pump activity in human term newborns and their mothers at delivery," Environmental Health Perspectives, vol. 116, no. 2, pp. 263-267, 2008.

[34] D. Mergler, H. A. Anderson, L. H. M. Chan, et al., "Methylmercury exposure and health effects in humans: a worldwide concern," Ambio, vol. 36, no. 1, pp. 3-11, 2007.

[35] J. Filser, H. Koehler, A. Ruf, J. Rombke, A. Prinzing, and M. Schaefer, "Ecological theory meets soil ecotoxicology: challenge and chance," Basic and Applied Ecology, vol. 9, no. 4, pp. 346-355, 2008.

[36] C. A. M. van Gestel, "Physico-chemical and biological parameters determine metal bioavailability in soils," Science of the Total Environment, vol. 406, no. 3, pp. 385-395, 2008.

[37] G. A. Sokolik, S. V. Ovsiannikova, T. G. Ivanova, and S. L. Leinova, "Soil-plant transfer of plutonium and americium in contaminated regions of Belarus after the Chernobyl catastrophe," Environment International, vol. 30, no. 7, pp. 939-947, 2004.

[38] C. Zhao, J. Ren, C. Xue, and E. Lin, "Study on the relationship between soil selenium and plant selenium uptake," Plant and Soil, vol. 277, no. 1-2, pp. 197-206, 2005.

[39] H.-H. Liste and I. Prutz, "Plant performance, dioxygenaseexpressing rhizosphere bacteria, and biodegradation of weathered hydrocarbons in contaminated soil," Chemosphere, vol. 62, no. 9, pp. 1411-1420, 2006.

[40] H. G. van der Geest and M. Leon Paumen, "Dynamics of metal availability and toxicity in historically polluted floodplain sediments," Science of the Total Environment, vol. 406, no. 3, pp. 419-425, 2008.

[41] A. Brouwer, U. G. Ahlborg, M. van den Berg, et al., "Functional aspects of developmental toxicity of polyhalogenated aromatic hydrocarbons in experimental animals and human infants," European Journal of Pharmacology, vol. 293, no. 1, pp. 1-40, 1995.

[42] M. Rutgers, J. Tuinstra, J. Spijker, M. Mesman, A. Wintersen, and L. Posthuma, Risico's voor het ecosysteem in stap twee van het saneringscriterium [Ecosystem risks in step 2 of the remediation criterion]. Bilthoven (the Netherlands): RIVM, 2008.

[43] J. Li, B. Zhou, Y. Liu, Q. Yang, and W. Cai, "Influence of the coexisting contaminants on bisphenol A sorption and desorption in soil," Journal of Hazardous Materials, vol. 151, no. 2-3, pp. 389-393, 2008.

[44] C. Gennings, W. H. Carter Jr., M. Casey, V. Moser, R. Carchman, and J. E. Simmons, "Analysis of functional effects of a mixture of five pesticides using a ray design," Environmental Toxicology and Pharmacology, vol. 18, no. 2, pp. 115-125, 2004.

[45] T. B. Hayes, P. Case, S. Chui, et al., "Pesticide mixtures, endocrine disruption, and amphibian declines: are we underestimating the impact?" Environmental Health Perspectives, vol. 114, supplement 1, pp. 40-50, 2006.

[46] M. J. Perry, S. A. Venners, D. B. Barr, and X. Xu, "Environmental pyrethroid and organophosphorus insecticide exposures and sperm concentration," Reproductive Toxicology, vol. 23, no. 1, pp. 113-118, 2007.

[47] C. A. Laetz, D. H. Baldwin, T. K. Collier, V. Hebert, J. D. Stark, and N. L. Scholz, "The synergistic toxicity of pesticide mixtures: implications for risk assessment and the conservation of endangered Pacific salmon," Environmental Health Perspectives, vol. 117, no. 3, pp. 348-353, 2009.

[48] D. De Zwart and L. Posthuma, "Complex mixture toxicity for single and multiple species: proposed methodologies," Environmental Toxicology and Chemistry, vol. 24, no. 10, pp. 2665-2676, 2005.

[49] R. Altenburger, H. Walter, and M. Grote, "What contributes to the combined effect of a complex mixture?" Environmental Science \& Technology, vol. 38, no. 23, pp. 6353-6362, 2004.

[50] J. Filser, R. Wittmann, and A. Lang, "Response types in Collembola towards copper in the microenvironment," Environmental Pollution, vol. 107, no. 1, pp. 71-78, 2000.

[51] J. W. Drexler and W. J. Brattin, "An in vitro procedure for estimation of lead relative bioavailability: with validation," Human and Ecological Risk Assessment, vol. 13, no. 2, pp. 383401, 2007.

[52] K. O'Halloran, “Toxicological considerations of contaminants in the terrestrial environment for ecological risk assessment," Human and Ecological Risk Assessment, vol. 12, no. 1, pp. 7483, 2006.

[53] J. Römbke, "Tools and techniques for the assessment of ecotoxicological impacts of contaminants in the terrestrial environment," Human and Ecological Risk Assessment, vol. 12, no. 1, pp. 84-101, 2006.

[54] P. H. Roos, S. Tschirbs, F. Pfeifer, et al., "Risk potentials for humans of original and remediated PAH-contaminated soils: application of biomarkers of effect," Toxicology, vol. 205, no. 3, pp. 181-194, 2004.

[55] R.-Y. Xiao, Z. Wang, C.-X. Wang, G. Yu, and Y.-G. Zhu, "Genotoxic risk identification of soil contamination at a major industrialized city in northeast China by a combination of in vitro and in vivo bioassays," Environmental Science \& Technology, vol. 40, no. 19, pp. 6170-6175, 2006.

[56] D.-H. Lee, J.-S. Lim, K. Song, Y. Boo, and D. R. Jacobs Jr., "Graded associations of blood lead and urinary cadmium 
concentrations with oxidative-stress-related markers in the U.S. population: results from the third National Health and Nutrition Examination Survey," Environmental Health Perspectives, vol. 114, no. 3, pp. 350-354, 2006.

[57] H.-G. Neumann, "Toxic equivalence factors, problems and limitations," Food and Chemical Toxicology, vol. 34, no. 11-12, pp. 1045-1051, 1996.

[58] I. D. Dobrev, M. E. Andersen, and R. S. H. Yang, "In silico toxicology: simulating interaction thresholds for human exposure to mixtures of trichloroethylene, tetrachloroethylene, and 1,1,1-trichloroethane," Environmental Health Perspectives, vol. 110, no. 10, pp. 1031-1039, 2002.

[59] E. Silva, N. Rajapakse, and A. Kortenkamp, "Something from "nothing"-eight weak estrogenic chemicals combined at concentrations below NOECs produce significant mixture effects," Environmental Science \& Technology, vol. 36, no. 8, pp. 1751-1756, 2002.

[60] M. Richter and B. I. Escher, "Mixture toxicity of reactive chemicals by using two bacterial growth assays as indicators of protein and DNA damage," Environmental Science \& Technology, vol. 39, no. 22, pp. 8753-8761, 2005.

[61] D. Wölfe, "Interactions between 2,3,7,8 TCDD and PCs as tumor promoters: limitations of TEFs," Teratogenesis, Carcinogenesis and Mutagenesis, vol. 17, pp. 217-224, 1997.

[62] W. R. Reeves, R. Barhoumi, R. C. Burghardt, et al., "Evaluation of methods for predicting the toxicity of polycyclic aromatic hydrocarbon mixtures," Environmental Science \& Technology, vol. 35, no. 8, pp. 1630-1636, 2001.

[63] H. A. El-Masri, M. M. Mumtaz, and M. L. Yushak, "Application of physiologically-based pharmacokinetic modeling to investigate the toxicological interaction between chlorpyrifos and parathion in the rat," Environmental Toxicology and Pharmacology, vol. 16, no. 1-2, pp. 57-71, 2004.

[64] A. Kortenkamp and R. Altenburger, "Approaches to assessing combination effects of oestrogenic environmental pollutants," Science of the Total Environment, vol. 233, no. 1-3, pp. 131$140,1999$.

[65] J. P. Sumpter and A. C. Johnson, "Lessons from endocrine disruption and their application to other issues concerning trace organics in the aquatic environment," Environmental Science \& Technology, vol. 39, no. 12, pp. 4321-4332, 2005.

[66] J. V. Brain, C. A. Harris, M. Scholze, et al., "Accurate prediction of the response of freshwater fish to a mixture of estrogenic chemicals," Environmental Health Perspectives, vol. 113, no. 6, pp. 721-728, 2005.

[67] C. A. Marchant, "Prediction of rodent carcinogenicity using the DEREK system for 30 chemicals currently being tested by the National Toxicology Program," Environmental Health Perspectives, vol. 104, pp. 1065-1073, 1996.

[68] H. J. M. Verhaar, J. R. Morroni, K. F. Reardon, et al., "A proposed approach to study the toxicology of complex mixtures of petroleum products: the integrated use of QSAR, lumping analysis and PBPK/PD modeling," Environmental Health Perspectives, vol. 105, supplement 1, pp. 179-195, 1997.

[69] C. N. Stevenson, L. A. Macmanus-Spencer, T. Luckenbach, R. G. Luthy, and D. Epel, "New perspectives on perfluorochemical ecotoxicology: inhibition and induction of an efflux transporter in the marine mussel, Mytilus californianus," Environmental Science \& Technology, vol. 40, no. 17, pp. 5580$5585,2006$. 

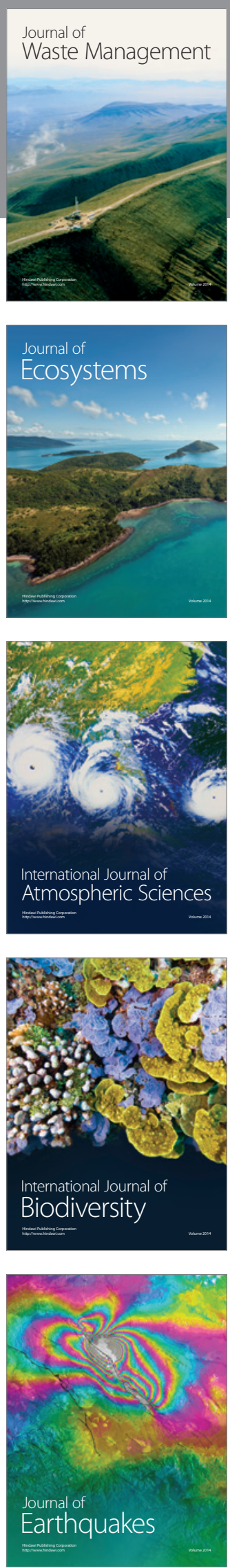
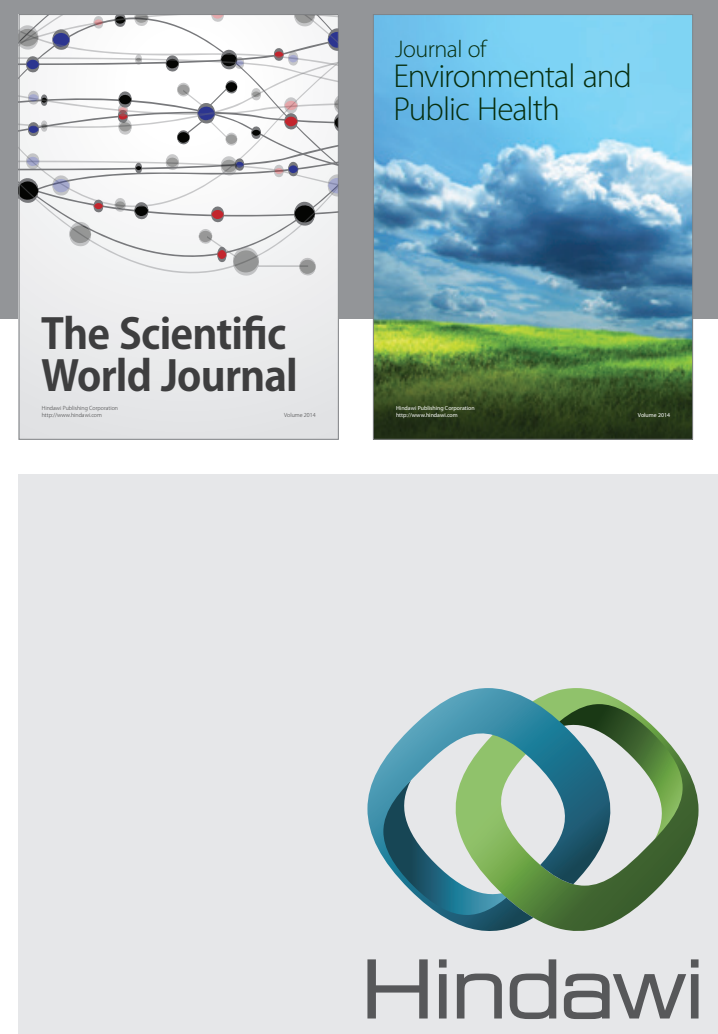

Submit your manuscripts at

http://www.hindawi.com
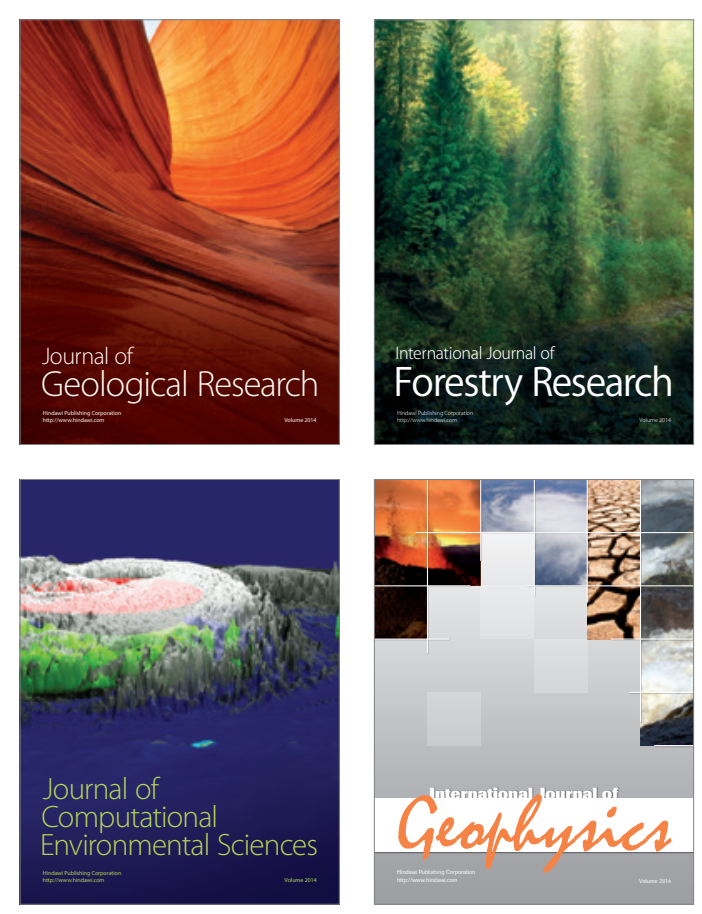
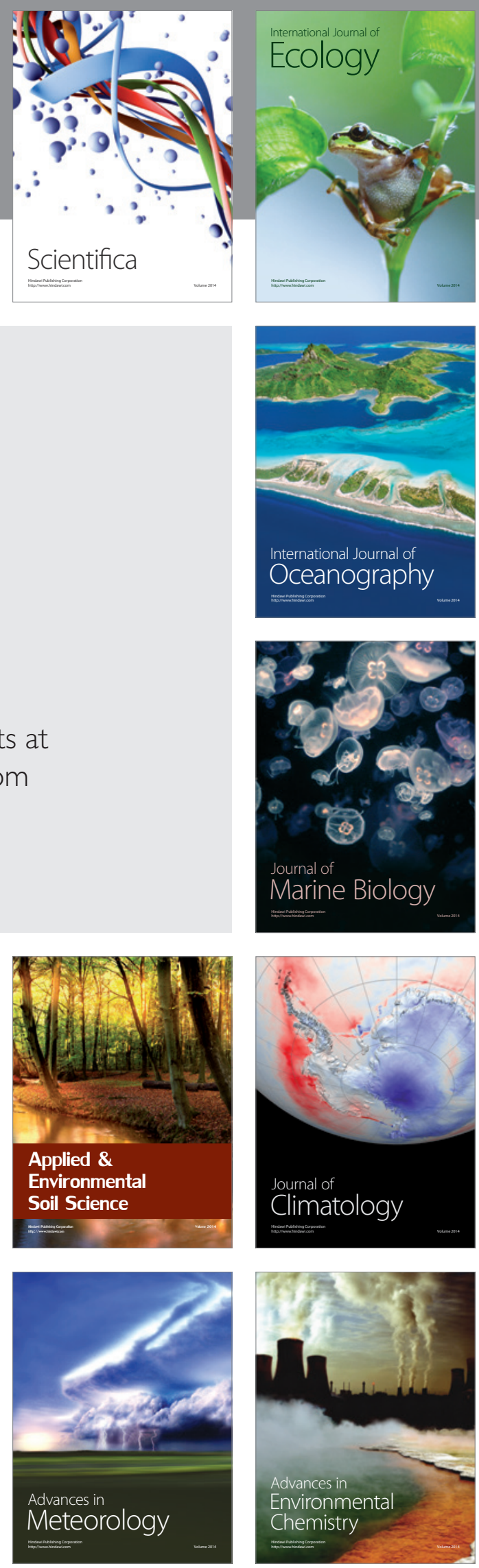